\title{
Investigation on the Feasibility of Establishing an Anti-fraud Platform in Colleges and Universities
}

\author{
Xiyu Liu ${ }^{1, a, *}$ Zhichen $\mathrm{Li}^{1, \mathrm{~b}}$ \\ ${ }^{1}$ School of Business Administration, HOHAI University, Changzhou Jiangsu, 213022, China
}

\begin{abstract}
The model of anti-fraud platform in colleges and universities highlights the crucial role of the combination of colleges and universities with large data in combating fraud. It aims to solve various problems such as the lack of legal provision in small-sum fraud, and forms a radiation circle of anti-fraud centred on colleges and universities. By analysing existing research achievements and challenges of anti-fraud platform in colleges and universities, this paper makes an in-depth discussion on the mode of anti-fraud platform in colleges and universities.
\end{abstract}

\section{Background}

At present, the social economy is developing in an allround way and the shared environment is complicated. The complex social environment has spawned many social security issues ${ }^{[1]}$. With the rapid development of social economy and the popularization of network and smart phone in China, fraud has become a high-frequency and frequently-occurring type of crime with extensive coverage, serious social harm and rapid growth in the economic field. ${ }^{[2]}$

College students have been one of the main deceived victims because of their shallow social experience and lack of experience. At the same time, with the increasing "socialization" of College campuses ${ }^{[3]}$, some criminals frequently extend their dirty hands of fraud into colleges and universities. Depending on a survey conducted by the Joint Social Survey Center of China Youth Daily, 70.5\% of the respondents admitted that they or the people around them had been cheated during their college years. The online fraud data research report for the first half of 2017 , published on June 20 by the first police-civilian joint network fraud reporting platform, Hunting Network Platform, also shows that nearly half of the victims of online fraud are post-90s College students. The cases of college students being swindled caused great loss of property and mental trauma to college students. At present, China has a relatively perfect legal system and treatment measures for huge amount of fraud, but the measures for small-amount of fraud have not been established ${ }^{[4]}$. The minimum amount for filing fraud in China is 2000 yuan, which makes a large part of fraud seize this vacancy to commit crime. However, it is very difficult for university students to safeguard their rights in frequent cases of cheating ${ }^{[5]}$. Therefore, how to effectively reduce and prevent the occurrence of small-amount of cheating incidents among college students has become an urgent problem to be solved.
To solve this problem, the most urgent task is to create an anti-fraud platform in colleges and universities, starting from the core of the fraudulent consciousness to solve the small-amount of fraud incidents. "The lack of restraint and the absence of incentives" are the principal problems of China's anti-fraud mechanism. Therefore, China's anti-fraud mechanism should adopt the strategy of "strengthening restraint, moderate incentive, and restraint and incentive implementation" ${ }^{[6]}$. Throughout the antifraud situation and experience of various countries and regions in the world, based on China's actual national conditions, specific to the "anti-fraud incentive mechanism" level design, should be led by the government to carry out a series of anti-fraud legal system construction, including the standardization and institutionalization of incentive mechanism, material incentives and spiritual incentives simultaneously ${ }^{[7-8]}$, the establishment of information-sharing mechanism. In view of the small amount of fraud incidents among college students, colleges and universities can help to establish an information sharing mechanism and platform.

\section{Necessity and feasibility analysis of platform establishment}

\subsection{Fully integrate the social background of the time.}

The Internet age makes the scope of people's activities expand and the societal environment complicated, so all kinds of security problems inevitably appear. And the research on the current situation and Countermeasures of small amount cheated has a strong character of the time.

\subsection{The data of the subjects are highly available and reliable.}

\footnotetext{
* Corresponding author:18761159527@163.com
} 
In conformity with the requirements of the time, the platform is built around the university students as the main object, it has a wider range, fewer constraints, strong data availability, and more authentic information.

\subsection{University Technology and talents are full of resources.}

In the process of establishing anti-fraud platform in colleges and universities, colleges and universities, at the top of China's education industry, as the "incubator" of intelligence and the "seeder" of knowledge, have obvious advantages in technology and human resources. Whether its knowledge system construction, network platform construction or anti-fraud skills training, colleges and universities have an irreplaceable role and advantages, which have greatly solved the problems of talent and technology in building platform.

\subsection{The guidance of universities is fierce.}

The guidance of anti-fraud in colleges and universities can be embodied in the following two aspects: firstly, it can guide students to enhance their understanding and understanding of external fraud knowledge, enhance their awareness of fraud prevention and enhance their vigilance; secondly, it can guide the investment of the surrounding universities and related social forces, including teachers, students, alumni and their counterparts. His involvement in the main body and participation is easy to lead and form huge human and financial power.

\section{Challenges facing the establishment of anti-fraud platforms in Universities.}

Firstly, in view of the complexity of the departments and industries involved in anti-fraud work, the implementation of the anti-fraud work requires greater expenditure and cost input.The operation of the platform requires manpower and funds, if not in a cooperative manner. It will be difficult for the anti-fraud platform to operate for a long time.

Secondly, China's current system cannot effectively mobilize the regulatory enthusiasm of the regulatory body, in order to share interests, regulatory bodies may relax regulatory attitude, or even participate in fraud, which is a great challenge to the establishment of the platform. The scope of fraud is very extensive and the consequences are expected to be very serious. If fraud cannot be effectively curbed, it will do serious harm to the property of the masses.

\section{University anti-fraud platform mode operation mechanism.}

\subsection{Building an anti-fraud information sharing platform.}

In order to ensure the normal operation of the platform, avoid the danger of insufficient expenditure and maintain a virtuous circle. The first step is to establish a monitoring information platform covering the city-level area where the university is located through advanced Internet technology. Then, through Internet technology to establish anti-fraud database including designated commercial streets, stations and other places where fraud incidents occur frequently, and collect and collate fraud data and cases in relevant areas.

\subsection{Establish information sharing mechanisms at the operational level.}

The competent departments of public security, industry and commerce, taxation, finance, food and drug supervision, banking supervision and insurance supervision shall share resources on pertinent business data of social insurance. This can largely avoid the Oolong incident caused by poor communication between departments. Especially in the context of the Internet and big data era, the implementation of monitoring and information-sharing through the Internet at the practical level will be helpful to discover the types of fraud and the trend of fraud in time, and it is also conducive to carry out targeted anti-fraud activities.

\subsection{Establish protection and publicity system for informants on the platform.}

China should learn from the American informants' protection clauses and the mechanism of sharing fines. China's existing laws, involving informants are: Article 41 of the Constitution, Article 254 of the Criminal Law and Article 84 and 85 of the Criminal Procedure Law on the rights of citizens and the obligation to protect informants' related provision. There are also rewards for whistleblowers in some local social insurance anti-fraud laws. However, in practice, China's informants are also faced with the risk of retaliation, some scholars' statistics, "in the prosecution reported suspecting crime of the whistleblower, about $70 \%$ of the informants suffered varying degrees of retaliation or disguised attack retaliation." From the perspective of cost-benefit analysis, it is obvious that the protection and incentive of the informant are not enough. Therefore, the platform should establish an informant protection, anonymous reporting and the protection of informants' personal information to relieve the fear of retaliation against the informants, so that the reporting behavior can be performed safely.

\subsection{Further establish cooperative relations with local law firms.}

Good cooperative relationship will enable college students and neighboring residents to contact local law firms directly through the platform for consultation, so that the deceived can quickly understand the situation and make decisions. At the same time, for small-amount of deceived, it will be realized that different victims of the same fraud are brought together on the basis of the 
platform, so that the amount involved in the case exceeds the minimum amount of money on file, thus realizing the filing of the case. And the realization of this behavior requires good coordination between the platform and the law firm.

\section{Conclusions}

The establishment of anti-fraud platform in colleges and universities will arouse people's attention to all kinds of fraud to a greater extent and raise college students' awareness of prevention. It can also reduce the occurrence of fraud cases in colleges and universities, especially reduce the occurrence of small-sum fraud among college students. It will be able to provide a certain reference for the prevention of small-amount fraud and the countermeasures after being fraudulent, then curb the rampancy of fraudsters. It can effectively reduce the loss that college students cannot recover and safeguard rights due to small-amount of fraud. At the same time, through in-depth analysis of collected data and comparison of relevant cases, the platform can effectively reflect the shortcomings and loopholes of existing measures, helping the government to formulate more effective policies and promote the improvement of relevant laws and regulations, then create a healthy and safe social environment and promote the establishment of a harmonious society.

\section{Acknowledgement}

This research was financially supported by the Science and Technology Fund for University Students(The current situation and case study of College Students' small amount cheated)

\section{References}

1. Wang Lijie, Liu Yan, Social security anti-fraud countermeasures and thinking .J. Shandong labor security, 6(2005).

2. $\mathrm{Xu}$ Qingzhao, The present situation, problems and Countermeasures of social insurance system in Shandong .J. Journal of Theory, 9(2010).

3. Li Yongjie, Research on the Framework of Social Medical Insurance System Innovation-Based on Principal-Agent Theory.J. Guangxi Social Science,4(2009).

4. Li Bensen. Broken windows theory and American crime control .J. Chinese Social Sciences, 5(2010).

5. Liu Xihua, Wei Chao. Summary of research on social medical insurance fraud in China .J. Oriental forum, 6(2013).

6. Sun Tong. Organizational behavior .M. Higher education press, 2005.

7. Cai Jihong, Maslow needs hierarchy theory to review.J. Theory circle, 5(2011).
8. Feng Lin. Incentive Model in Legal Governance: Hypothesis, Theory and Practice .J. Legal System and Social Development, 2(2012). 